University of Wollongong

Research Online

Faculty of Engineering - Papers (Archive)

Faculty of Engineering and Information

Sciences

1999

\title{
Critical current degradation caused by winding process of Bi-2223/Ag HTS wire in the form of a coil
}

Jian X. Jin

University of Wollongong

S X. Dou

University of Wollongong, shi@uow.edu.au

Hua-Kun Liu

University of Wollongong, hua@uow.edu.au

T Hardono

University of Wollongong

Christopher D. Cook

University of Wollongong, chris_cook@uow.edu.au

See next page for additional authors

Follow this and additional works at: https://ro.uow.edu.au/engpapers

Part of the Engineering Commons

https://ro.uow.edu.au/engpapers/4351

\section{Recommended Citation}

Jin, Jian X.; Dou, S X.; Liu, Hua-Kun; Hardono, T; Cook, Christopher D.; and Grantham, C.: Critical current degradation caused by winding process of Bi-2223/Ag HTS wire in the form of a coil 1999, 138-141. https://ro.uow.edu.au/engpapers/4351

Research Online is the open access institutional repository for the University of Wollongong. For further information contact the UOW Library: research-pubs@uow.edu.au 


\section{Authors}

Jian X. Jin, S X. Dou, Hua-Kun Liu, T Hardono, Christopher D. Cook, and C. Grantham 


\title{
Critical Current Degradation Caused by Winding Process of Bi-2223/Ag HTS Wire in the Form of a Coil
}

\author{
J.X. Jin, S.X. Dou and H.K. Liu \\ Institute for Superconducting and Electronic Materials \\ University of Wollongong, Wollongong, NSW 2522, Australia \\ T. Hardono and C. Cook \\ Dept. of Electrical, Computer \& Telecommunications Eng. \\ University of Wollongong, NSW 2522, Australia \\ C. Grantham \\ Dept. of Electric Power \\ University of NSW, Sydney, NSW 2052, Australia
}

\begin{abstract}
High $\mathrm{T}_{\mathrm{c}}$ superconducting (HTS) (Bi,Pb) ${ }_{2} \mathrm{Sr}_{2} \mathrm{Ca}_{2}$ $\mathrm{Cu}_{3} \mathrm{O}_{10+x} \mathrm{Ag}$-clad wire has potential for practical applications in the form of a coil or a winding. This HTS wire has strong magnetic field-dependent and mechanical strain-dependent critical currents, consequently it faces a severe problem of critical current degradation when it is used in the form of a coil. To design a winding with this conductor, the critical current degradation has to be identified with relation to the magnetic fields and the winding process. This is important to optimize an appropriate coil winding procedure using this HTS wire. A specially designed non-inductive sample has been made with a $(\mathrm{Bi}, \mathrm{Pb})_{2} \mathrm{Sr}_{2} \mathrm{Ca}_{2}$ $\mathrm{Cu}_{3} \mathrm{O}_{10+x}$ Ag-clad 27-filament wire, and the critical current degradation, which is caused by the magnetic field generated and the mechanical winding procedure used to form a coil, has been separated into two factors accordingly, and discussed in this paper.
\end{abstract}

\section{INTRODUCTION}

$(\mathrm{Bi}, \mathrm{Pb})_{2} \mathrm{Sr}_{2} \mathrm{Ca}_{2} \mathrm{Cu}_{3} \mathrm{O}_{10+\mathrm{x}} \mathrm{Ag}$ clad HTS wire is one of the most promising candidates for magnets and electrical applications. In most of these applications, a wound form of the HTS wire is required. The critical current of the $(\mathrm{Bi}, \mathrm{Pb})_{2} \mathrm{Sr}_{2} \mathrm{Ca}_{2} \mathrm{Cu}_{3} \mathrm{O}_{10+x} \mathrm{Ag}$ clad HTS wire degrades when it is used in the form of a coil. The magnetic field generated and the winding procedure used are main factors which cause the critical current degeneration of the HTS wire. Theoretically, the degeneration can be calculated or evaluated by the relations of the critical current $I_{c}$ - magnetic field $B\left(B_{/ / c}\right.$ and $\left.B_{/ / a b}\right)$ and the wire strain $\varepsilon-I_{c}$. Practically, different coil configurations and winding procedures used will have different degrees of degeneration. It is necessary to distinguish the fractions which are caused by either the magnetic field or the winding procedure, so that the winding process can be optimized.

Manuscript received September 14, 1998.
A special non-inductive sample has been made which allows the $(\mathrm{Bi}, \mathrm{Pb})_{2} \mathrm{Sr}_{2} \mathrm{Ca}_{2} \mathrm{Cu}_{3} \mathrm{O}_{10+x} \mathrm{Ag}$ clad HTS wire critical current to be unaffected by the magnetic field generated. Therefore the degeneration caused by the winding procedure can be determined. By using this specially designed sample coil, the critical current degradation of the $(\mathrm{Bi}, \mathrm{Pb})_{2} \mathrm{Sr}_{2} \mathrm{Ca}_{2} \mathrm{Cu}_{3-}$ $\mathrm{O}_{10+x} \mathrm{Ag}$ clad HTS wire in the form of a winding has been investigated in this work.

\section{Critical Current Degeneration Of The Hts Wire WHEN FORMING A COIL}

Critical current degeneration of the $(\mathrm{Bi}, \mathrm{Pb})_{2} \mathrm{Sr}_{2} \mathrm{Ca}_{2} \mathrm{Cu}_{3-}$ $\mathrm{O}_{10+\mathrm{x}} \mathrm{Ag}$ clad HTS wire when it forms a coil, $\Delta \mathrm{I}_{\mathrm{c}(\text { coil }}$, is the difference between the HTS wire critical current $I_{c(\text { wire })}$ and the final HTS coil critical current $I_{\text {c(coil) }}$. It is related to the generated magnetic field and the winding procedure used in forming the HTS coil. The critical current degeneration for a HTS coil can be expressed by

$$
\Delta \mathrm{I}_{\mathrm{c}(\mathrm{coil})}=\Delta \mathrm{I}_{\mathrm{c}(\mathrm{f})}+\Delta \mathrm{I}_{\mathrm{c}(\mathrm{m})}+\Delta \mathrm{I}_{\mathrm{c}(\mathrm{c})}
$$

or

$$
\begin{aligned}
& \Delta \mathrm{I}_{\mathrm{c}(\text { coil })} / \mathrm{I}_{\mathrm{c}(\text { wire })}=\left[\Delta \mathrm{I}_{\mathrm{c}(\mathrm{f})} / \mathrm{I}_{\mathrm{c}(\text { wire })}\right]+\left[\Delta \mathrm{I}_{\mathrm{c}(\mathrm{m})} /\right. \\
&\left.\mathrm{I}_{\mathrm{c}(\text { wire })}\right]+\left[\Delta \mathrm{I}_{\mathrm{c}(\mathrm{c})} / \mathrm{I}_{\mathrm{c}(\text { wire })}\right]
\end{aligned}
$$

where $\Delta \mathrm{I}_{\mathrm{c}(\mathrm{f})}$ is the degeneration caused by the increased self magnetic field to form a HTS coil from the HTS wire, $\Delta \mathrm{I}_{\mathrm{c}(\mathrm{m})}$ is the degeneration caused by mechanical processing to form a HTS coil from the HTS wire, and $\Delta \mathrm{I}_{\mathcal{c}(\mathrm{c})}$ is the degeneration caused by changing cryogenic parameters due to forming a HTS coil from the HTS wire. For the HTS wire with a high percentage of $\mathrm{Ag}$ sheath cross-sectional area and operated by immersion in liquid nitrogen, the $\Delta \mathrm{I}_{c(c)}$ can be neglected, 
therefore (2) can be simplified by assuming $\left[\Delta \mathrm{I}_{\mathfrak{c ( c )}} / \mathrm{I}_{\mathrm{c}(\text { wire) }}\right] \sim$ 0 .

$\Delta \mathrm{I}_{\mathrm{c}(\mathrm{f})}$ can be analyzed by considering the magnetic field distribution components of $\mathrm{B}, \mathrm{B}_{/ / \mathrm{c}}$ and $\mathrm{B}_{/ / \mathrm{ab}}$. For a $(\mathrm{Bi}, \mathrm{Pb})_{2} \mathrm{Sr}_{2} \mathrm{Ca}_{2} \mathrm{Cu}_{3} \mathrm{O}_{10+\times} \mathrm{Ag}$ clad HTS wire operated by immersing in liquid nitrogen, the critical current degradation caused by the magnetic field and the winding mechanical strains are major factors for the total critical current degeneration of the HTS coil. This combined degeneration has to be separated to optimize the HTS coil winding processing techniques.

$\Delta \mathrm{I}_{\mathrm{c}(\mathrm{m})}$ can be analyzed by the wire mechanical strains caused by the winding procedure used. The HTS wire bending strain $\varepsilon_{\mathrm{b}}$ and tensile strain $\varepsilon_{\mathrm{l}}$ have been considered and investigated with relation to HTS coils [1-5]. Since the rotating torsion strain $\varepsilon_{\mathrm{r}}$ cannot be avoided during winding processing, it is also investigated in this work. The HTS wire mechanical strains caused by winding processing, can be described by

$$
\begin{aligned}
& \varepsilon_{l}=\left(L-L_{o}\right) / L_{o} \\
& \varepsilon_{b}=(1+2 R / t)^{-1}
\end{aligned}
$$

where $L_{0}$ is the original length of sample in the tensile test, $L$ is the length of sample after being extended by the applied uniaxial tensile force, $R$ is the radius of the bending curvature, $t$ is the thickness of sample.

The evaluation of the torsion shear strain $\varepsilon_{\mathrm{t}}$ can be based on

$$
\varepsilon_{\mathrm{t}}=\mathrm{r} \theta / \mathrm{L}_{\mathrm{o}}
$$

where $r$ is the radial distance measured from the center of the sample, $\theta$ is the angle of twist usually expressed in radians, and $L_{0}$ is the test length of the sample.

\section{The SPECially Designed Hts Sample}

A $(\mathrm{Bi}, \mathrm{Pb})_{2} \mathrm{Sr}_{2} \mathrm{Ca}_{2} \mathrm{Cu}_{3} \mathrm{O}_{10+\times} \mathrm{Ag}$ clad 27-core multifilament HTS wire, produced using the normal powder-in-tube techniques, has been selected. The HTS sample wire is about $8 \mathrm{~m}$ in length, having cross-section $3.4 \mathrm{~mm} \times 0.28 \mathrm{~mm}$. The area ratio of HTS / (HTS $+\mathrm{Ag}) \sim 27 \%$. The short sample critical currents measured are $\mathrm{I}_{\mathfrak{c}} \approx 20 \pm 4 \mathrm{~A}$. The designed non-inductance sample was wound under the normal react and wind procedure using the HTS wire in a configuration of insulated parallel double wires. The magnetic fields generated by the two wires are canceled by each other. The wire was insulated with Teflon tapes and insulation paper. The sample has a coil form, and it has $15 \times 2$ turns, $\phi_{\text {in }}=5 \mathrm{~cm}$, and $\phi_{\text {out }}=$ $11.5 \mathrm{~cm}$.

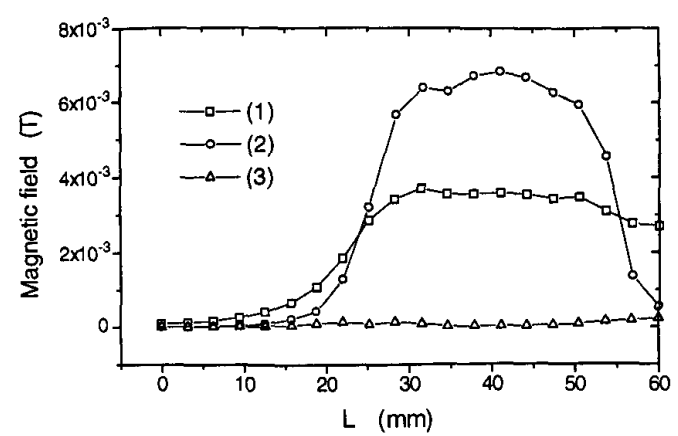

Fig. 1. Sample field distribution in comparison with normal coils.

The special sample configuration has been analyzed in comparison with normal coils as shown in Fig. 1, in which (1) represents the field generated by the wire in a normal coil form; (2) represents the wire in form of a pair of double pancakes having opposite generated magnetic fields; and (3) represents the used configuration for the sample which has no self-magnetic fields - effectively canceled. L in Fig. 1 represents the distance from the coil center $\mathrm{O}$ along the coil radius direction. The transport $D C$ current used for Fig. 1 is $7.2 \mathrm{~A}$. Since the sample magnetic field $B(B \approx I L / S$, where $L$ is the winding inductance, $I$ is the transport current, and $S$ is the enclosed winding area) has been effectively cancelled, the critical current is equivalent to the value with zero magnetic field condition. The sample HTS coil inductance is less than 1 $\mu \mathrm{H}$ measured using a R-C-L bridge.

\section{CRitical CuRrent Degeneration CaUSED By WINDING PROCESSING}

The special sample critical current measured is shown in Fig. 2, where the original wire critical current $I_{c}$ is also shown in the figure. At $1 \mu \mathrm{V} / \mathrm{cm}$ criterion, the sample coil has a critical current of $7.2 \mathrm{~A}$, and the original wire has a critical current of 13.8 A. At $10 \mu \mathrm{V} / \mathrm{cm}$ criterion, the sample has a critical current of $13.1 \mathrm{~A}$, and the original wire has a critical current of $19 \mathrm{~A}$.

To identify the critical current degeneration caused by the coil winding procedure, the HTS $\left(\mathrm{Bi}, \mathrm{Pb}_{2} \mathrm{Sr}_{2} \mathrm{Ca}_{2} \mathrm{Cu}_{3} \mathrm{O}_{10+\mathrm{x}} \mathrm{Ag}\right.$ clad multifilament wire critical current was measured under bending and torsion strains. The short HTS wires used for the bending test have a length of $2 \mathrm{~cm}$ and $1 \mathrm{~cm} \mathrm{~V}-\mathrm{V}$ terminals. Fig. 3 shows $I-V$ curves with different bending radius of a sample ( $\mathrm{S}-3$ with $\mathrm{I}_{\mathrm{c}}=22.8 \mathrm{~A}$ ), and having one direction single bending on selected formers. In Fig. 3, $\phi=$ inf. represents the sample straightened out. Fig. 4 shows $I_{c}-\varepsilon$ curves of different samples, where the $1 \mu \mathrm{V} / \mathrm{cm}$ criterion was used for $I_{c}$. 
Fig. 5 shows the torsion test arrangement of the short HTS wire sample, where $\theta$ is the angle of twist, and $L$ is the sample length. Fig. 6 is the I - V - $\theta$ curve for a sample having a length of $3.8 \mathrm{~cm}$ and $1 \mathrm{~cm} \mathrm{~V}-\mathrm{V}$ terminals, where the $\theta$ is changed from $0^{\circ}$ to $360^{\circ}$ as shown in the figure. Fig. 7 shows $I_{c}$ verse $\theta$ of two samples used having the same conditions, where the $1 \mu \mathrm{V} / \mathrm{cm}$ criterion was used for $\mathrm{I}_{\mathrm{c}}$.

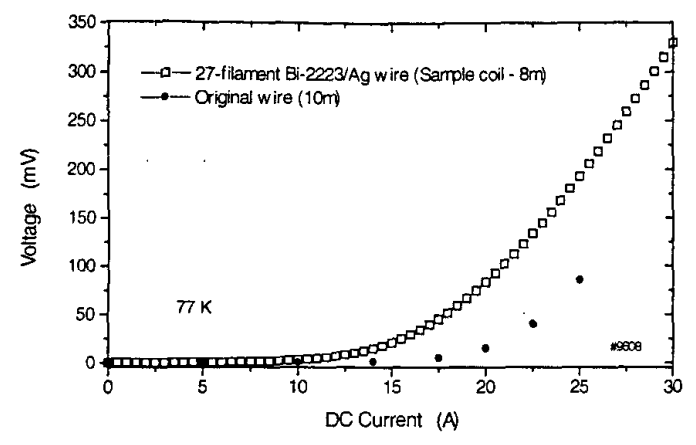

Fig. 2. Critical current of the sample.

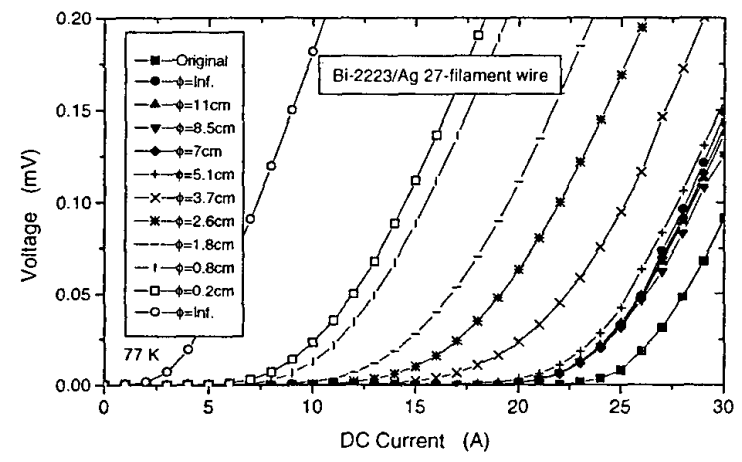

Fig. 3. I-V curves of a sample under different bending radius.

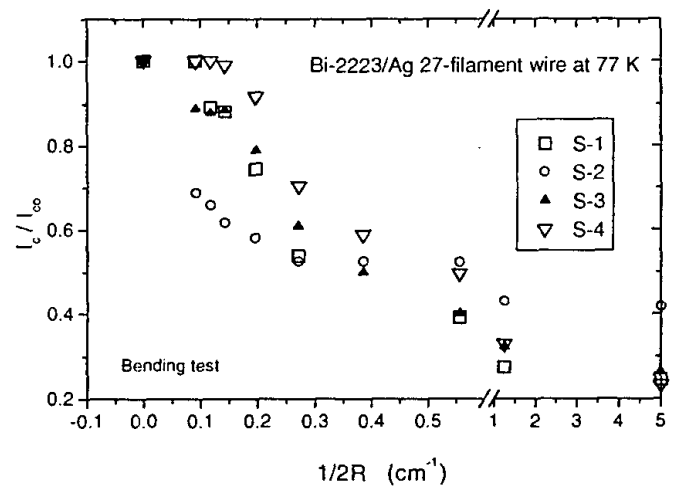

Fig. $4 . I_{c}-\varepsilon$ curves of the short samples.

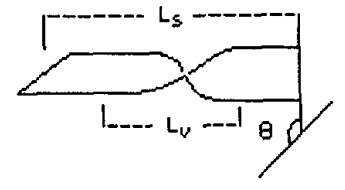

Fig. 5. Torsion test of the Bi-2223/Ag sample.

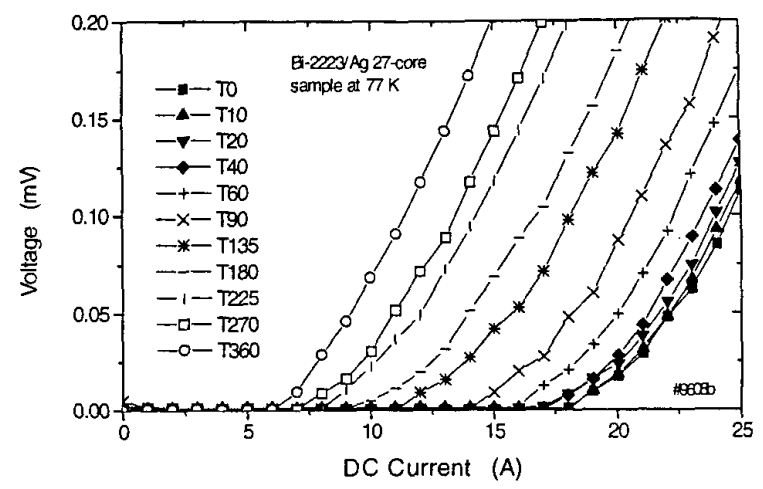

Fig. 6. I-V - $\theta$ curve of the short wire.

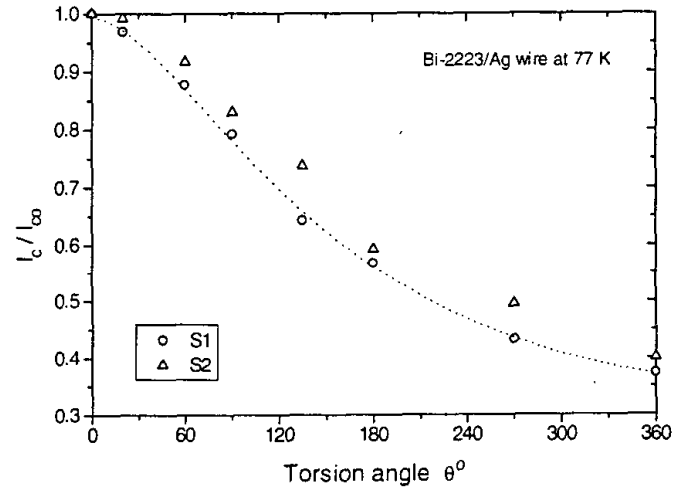

Fig. 7. $\mathbf{I}_{\mathrm{c}}-\theta$ curve of the short wires.

\section{DISCUSSION}

The critical current degradation of the $(\mathrm{Bi}, \mathrm{Pb})_{2} \mathrm{Sr}_{2} \mathrm{Ca}_{2} \mathrm{Cu}_{3-}$ $\mathrm{O}_{10+x} \mathrm{Ag}$ clad HTS wire caused by magnetic fields when it forms a coil can be evaluated from the field distributions, $\mathrm{B}_{/ / \mathrm{c}}$ and $\mathrm{B}_{/ / \mathrm{a} b}$, generated around the coil. However the mechanical strains occurred during forming a coil with the HTS wire have also created critical current degeneration of the HTS wire. The final critical current degeneration caused by the generated magnetic fields and the mechanical strains is a combination of these two factors. This combined value has to be separated to optimize a coil winding procedure with the 
$(\mathrm{Bi}, \mathrm{Pb})_{2} \mathrm{Sr}_{2} \mathrm{Ca}_{2} \mathrm{Cu}_{3} \mathrm{O}_{10+x} \mathrm{Ag}$ clad HTS wire. This has been achieved by using a specially designed non-inductive HTS coil. With this sample, the critical current degradation caused by a winding procedure can be identified by separating the part which is only affected by the mechanical strains established during the winding procedure.

The special sample critical current measured shows that when a coil having $\phi_{\text {in }}=5 \mathrm{~cm}$ and $\phi_{\text {out }}=11.5 \mathrm{~cm}$ is made the $(\mathrm{Bi}, \mathrm{Pb})_{2} \mathrm{Sr}_{2} \mathrm{Ca}_{2} \mathrm{Cu}_{3} \mathrm{O}_{10+x} \mathrm{Ag}$ clad HTS wire used has critical current degeneration caused by mechanical strains of $\Delta \mathrm{I}_{\mathrm{c}(\mathrm{m})}=$ $13.8 \mathrm{~A}-7.2 \mathrm{~A}=6.6 \mathrm{~A}$, and $\left[\Delta \mathrm{I}_{\mathrm{c}(\mathrm{m})} / \mathrm{I}_{\mathrm{c}(\text { wire })}\right] \sim 48 \%$ at $1 \mu \mathrm{V} / \mathrm{cm}$ criterion and in liquid nitrogen. At the $10 \mu \mathrm{V} / \mathrm{cm}$ criterion, $\left[\Delta \mathrm{I}_{\mathrm{c}(\mathrm{m})} / \mathrm{I}_{\mathrm{c}(\text { wire })}\right] \sim 31 \%$. This is a significant value for the HTS wire critical current degeneration. Therefore the final HTS coil critical current has a potential to be increased by optimizing the coil winding processing. The critical current degeneration caused by the mechanical strains is basically coming from the HTS wire mechanical bending strain $\varepsilon_{b}$, tensile strain $\varepsilon_{1}$, and torsion strain $\varepsilon_{\mathrm{t}}$.

From the samples used for the bending test, the $(\mathrm{Bi}, \mathrm{Pb})_{2} \mathrm{Sr}_{2} \mathrm{Ca}_{2} \mathrm{Cu}_{3} \mathrm{O}_{10+\times} \mathrm{Ag}$ clad 27-filament HTS wire has $\mathrm{I}_{\mathrm{c}} /$ $I_{c o}=90 \%$ when it is under $\varepsilon_{b}=20 \%$. This gives minimum bending diameter of $5 \mathrm{~cm}$. From Fig. 3, the critical current of the HTS wire decreases significantly when the wire bending diameter or the coil winding diameter is less than $5 \mathrm{~cm}$.

To form a coil from the final sintered $(\mathrm{Bi}, \mathrm{Pb})_{2} \mathrm{Sr}_{2} \mathrm{Ca}_{2} \mathrm{Cu}_{3}$ $\mathrm{O}_{10+x} \mathrm{Ag}$ clad HTS wire, the torsion strain cannot be avoided during the coil winding procedure. Therefore this has to be investigated. However, it does not reduce the critical currents of the HTS wires significantly for a normal HTS coil winding procedure, as can be seen from the results shown in Fig. 6 and Fig. 7. For a $3.8 \mathrm{~cm}$ sample, the critical current $90 \% \mathrm{I}_{\mathrm{co}}$ can be maintained when the sample twist angle $\theta$ is up to $60^{\circ}$, where $\varepsilon_{\mathrm{t}} \approx 5.5 \%$.

From the bending test result shown in Fig. 3, the $(\mathrm{Bi}, \mathrm{Pb})_{2} \mathrm{Sr}_{2} \mathrm{Ca}_{2} \mathrm{Cu}_{3} \mathrm{O}_{10+\mathrm{x}}$ Ag clad HTS short wire has a critical current degeneration when it is transferred from its original curve. This straightening process happened when transferring the sintered $(\mathrm{Bi}, \mathrm{Pb})_{2} \mathrm{Sr}_{2} \mathrm{Ca}_{2} \mathrm{Cu}_{3} \mathrm{O}_{10+\mathrm{x}} \mathrm{Ag}$ clad wire wound on the normal used $\mathrm{Al}_{2} \mathrm{O}_{3}$ tube to form the final coil. For the HTS wire used, it was transferred from the $90 \mathrm{~cm} \mathrm{Al}_{2} \mathrm{O}_{3}$ tube used for the wire sintering and was straighten, and this reduces the critical current by about $12.3 \%(22.8-20 \mathrm{~A} /$ $22.8 \mathrm{~A}$ ) based on the short sample with the $1 \mu \mathrm{V} / \mathrm{cm}$ criterion and liquid nitrogen operation.

\section{CONCLUSION}

A special non-inductive HTS coil has been made by using a $(\mathrm{Bi}, \mathrm{Pb})_{2} \mathrm{Sr}_{2} \mathrm{Ca}_{2} \mathrm{Cu}_{3} \mathrm{O}_{10+x} \mathrm{Ag}$ clad 27-core multifilament HTS wire, through a react and wind procedure. By using this specially designed HTS coil, the critical current degeneration due to forming a coil has been analyzed by the separation of the magnetic field influence and the mechanical strain influence. This separation would allow a HTS coil winding procedure to be identified and therefore to be optimized. For the sample HTS coil made, the HTS wire critical current degeneration caused by mechanical strains is $\left[\Delta \mathrm{I}_{\mathrm{c}(\mathrm{m})} / \mathrm{I}_{\mathrm{c}(\text { wire })}\right] \sim$ $48 \%$. The sample test results show that a HTS coil critical current is able to be optimized by reducing mechanical strains in a properly designed coil winding procedure. The mechanical strain effects have been verified by the measurements of the bending strain and the torsion strain of the $(\mathrm{Bi}, \mathrm{Pb})_{2} \mathrm{Sr}_{2} \mathrm{Ca}_{2} \mathrm{Cu}_{3} \mathrm{O}_{10+x} \mathrm{Ag}$ clad 27-filament HTS wire. The relation of the torsion strain and the critical current of the $(\mathrm{Bi}, \mathrm{Pb})_{2} \mathrm{Sr}_{2} \mathrm{Ca}_{2} \mathrm{Cu}_{3} \mathrm{O}_{10+x} \mathrm{Ag}$ clad multifilament HTS wire was firstly investigated in this work. The torsion test result shows that the torsion strain of this HTS wire during normal HTS coil winding procedure could be neglected.

\section{ACKNOWLEDGMENT}

The authors would like to thank Dr. Y.C. Guo, and Dr. J.N. $\mathrm{Li}$ for providing help and discussion to the work.

\section{REFERENCES}

[1] S.X. Dou and H.K. Liu, "Ag-sheathed $\mathrm{Bi}(\mathrm{Pb}) \mathrm{SrCaCuO}$ superconducting tapes," Supercond. Sci. Technol., vol. 6, pp. 297-314, 1993.

[2] K. Sato, T. Hikata, H. Mukai, M. Ueyama, N. Shibuta, T. Kato, T. Masuda, M. Nagata, K. Iwata, and T. Mitsui, "High- $\mathrm{J}_{\mathrm{c}}$ silversheathed Bi-based superconducting wires," IEEE Trans. Mag., vol. 27, pp. 1231-1238, 1991.

[3] S.X. Dou, Y.C. Guo, J. Yau, J.X. Jin, and H.K. Liu, "Mechanical properties of Ag-clad Bi-based superconducting composite tapes," Physics B, vol. 194-196, pp. 1577-1578, 1994.

[4] J.X. Jin, S.X. Dou, C. Grantham, and H.K. Liu, "Preparation of high $T_{\mathfrak{c}}$ superconducting coils for consideration of their use in a prototype fault current limiter," IEEE Trans. Appl. Supercond., vol. 5, no. 2, pp. 1051-1054, 1995.

[5] J.X. Jin, C. Grantham, H.K. Liu, and S.X. Dou, "(Bi, $\mathrm{Pb}_{2} \mathrm{Sr}_{2} \mathrm{Ca}_{2} \mathrm{Cu}_{3}-$ $\mathrm{O}_{10+\mathrm{x}} \mathrm{Ag}$-clad high- $\mathrm{T}_{\mathrm{c}}$ superconducting coil and its magnetic field properties," Philosophical Magazine B, vol. 75, no. 6, pp. 813-826, 1997. 